\title{
The school-leaver time bomb
}

Richard Pearson

\section{The decline in the number of school-leavers means that to remain competitive, employers will have to change their strategies for recruitment and training.}

EARlier this year, one in eight British employers surveyed thought that the number of school-leavers would increase over the next five years, while a further one in four could not give any estimate of what was likely to happen (Fig. 1). Many of them were major recruiters of schoolleavers. Few companies are considering adjusting their recruitment policies. Yet it is well known that the decline in numbers of school-leavers will be dramatic, over 35 per cent in the decade to 1993 (Nature 329. $470 ; 1987)$. The decline is most pronounced in the high unemployment areas of the North and the Midlands, and weakest in the booming South-East. The fall is likely to be highest among the least qualified, again auguring well for the unemployment problem. Even so, the drop of more than 20 per cent among those with five $\mathrm{O}$ levels and two A levels is dramatic, particularly as the top 20 recruiters alone take half of those with two A levels going into jobs.

The government is now embarking on a campaign to alert employers to these changes, which are being mirrored in most of the Western world. What then should recruiters be doing about it, and where is the decline likely to hit hardest?

Employers recruit young people for a variety of reasons, for example for their skills, as trainees, because they are cheap

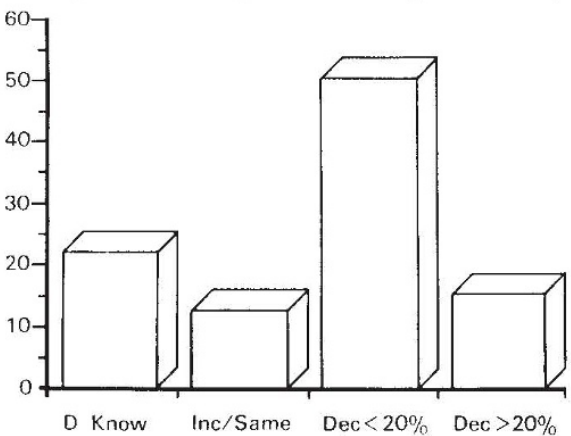

Fig. 1 In answer to the question "What will happen to youth labour supply by 1993?", few employers foresee the large decrease. Data from Employer Response to the Decline in School Leavers, IMS, 1988.

or because they are available. The Youth Training Scheme (YTS) is now a key entry channel for young people into many jobs; the direct recruitment of 16-17-year-olds is falling in importance as YTS is increasingly seen as the basis for developing broad-based abilities in young people. Where higher qualification levels are required, 18-21-year-olds are sought. The same is true in, for example, shift working, where legislation restricts the use of younger workers.

Despite the shortage of school-leavers, the total labour force will grow by nearly a million over the period to 1995 , with the growth being dominated by women, many of whom will be returning to work. Yet for most companies, re-entrants to the labour market are not seen as a significant source of recruitment. Internal appointments and retraining also remain a largely untapped source of new entrants, despite the advantages of using staff who are already familiar with many aspects of the organization. Although many employers are clearly dependent on young people, there seems no objective reason for their being the chief and, in some cases, the exclusive source of entrants.

This may be one reason for the general lack of awareness among employers of the marked changes coming to school-leaver supply, and their lack of preparation for the consequences (Fig. 2). Employers in the public sector, financial services, construction and transport were generally the best informed, with retailers, hoteliers and caterers the least well informed. Awareness among the larger companies often did not spread beyond the head office or the personnel function.

Given this lack of awareness, it is not surprising that few companies were planning to change their recruitment, training or employment strategies. Where they had thought about the problem, the most common response was to try to increase the attractiveness of their jobs through improved liaison with schools and colleges, better marketing of vacancies and improved training and career prospects, the latter being seen as more relevant than increasing wages. Unfortunately, these strategies simply increase market share in a shrinking market. But the emphasis being given to training augurs well for the long-term development of the United Kingdom's skill base. Another important and desirable strategy is the substitution of YTS entrants for more highly qualified recruits. But many of these companies are already having problems filling their existing YTS places and they will have to improve the attractiveness of their schemes to maintain intakes, let alone to increase them.

Among other options, the importance of retraining is increasingly being recog- nized but was not expected to make a significant contribution. A few large organizations have started reducing entry standards or introducing aptitude testing in place of a qualification-based selection. Few, however, had started looking to new sources of recruits such as the married women returners, the unemployed, mature entrants or other sources. Finally, in a few instances, companies were introducing new technology or productivity improvement programmes to reduce the demand for staff, or relocating to easier labour markets, although such action was usually prompted by other business considerations.

As awareness of the problem grows, the most likely response is to try to increase

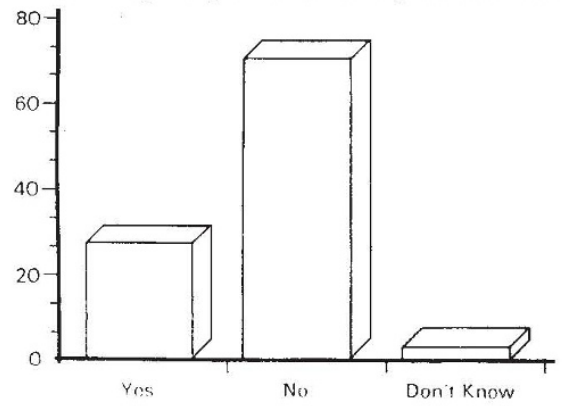

Fig. 2 Few employers answer "yes" when asked "Are you considering revising recruitment policies?"

market share. All this presupposes that nothing else is happening. But in the most pressured part of the market, those with five or more O levels, or two A levels, additional pressure is coming from the education system to get more pupils to stay in education longer.

Who then will win the battle for the bright school-leaver with numerate $\mathrm{O}$ and A levels? The banks offering high salaries, good training and career prospects, or the engineering courses in polytechnics offering good long-term career prospects, but initially small grants or loans? The clear losers will be organizations unable or unwilling to adapt their recruitment strategies and reward structures in the light of increased competition. The winners will be the young, particularly those with good skills and motivation who are prepared to follow the jobs and opportunities to those parts of the economy where they exist.

Richard Pearson is at the Institute of Manpower Studies, Mantell Building, University of Sussex, Brighton BN1 9RF, UK. 